19 Revue d'histoire du XIXe siècle

Société d'histoire de la révolution de 1848 et des

révolutions du XIXe siècle

$1 \mid 1985$

Varia

\title{
Daniel LICOU [dir.], Histoire de Montauban
}

Toulouse, Éditions Privat, 1984, 350 p., collection "Pays et Villes de France".

Jean-Claude Caron

\section{OpenEdition}

Journals

Édition électronique

URL : http://journals.openedition.org/rh19/359

DOI : 10.4000/rh19.359

ISSN : $1777-5329$

Éditeur

La Société de 1848

Édition imprimée

Date de publication : 1 juin 1985

ISSN : 1265-1354

Référence électronique

Jean-Claude Caron, «Daniel LICOU [dir.], Histoire de Montauban », Revue d'histoire du XIXe siècle [En ligne], 1 | 1985, mis en ligne le 28 octobre 2002, consulté le 22 septembre 2020. URL : http:// journals.openedition.org/rh19/359; DOI : https://doi.org/10.4000/rh19.359

Ce document a été généré automatiquement le 22 septembre 2020

Tous droits réservés 


\section{Daniel LICOU [dir.], Histoire de Montauban}

Toulouse, Éditions Privat, 1984, 350 p., collection "Pays et Villes de France".

Jean-Claude Caron

Privat publie un nouveau volume de sa très belle collection d'histoire régionale. Montauban méritait cet honneur, car la "Genève française" n'avait guère été étudiée dans son ensemble depuis le siècle dernier. Cet ouvrage, auquel ont participé seize collaborateurs, dresse un panorama complet du chef-lieu du Tarn-et-Garonne. La cité d'Ingres et de Bourdelle a une très ancienne histoire, que relatent les deux premiers chapitres. Mais c'est à partir du Moyen Âge que Montauban connait à la fois un premier essor économique --illustré au XIX ${ }^{e}$ siècle par les frères Bonis-- et ses premiers déchirements religieux, avec la crise albigeoise. La Guerre de Cent ans n'épargne pas non plus la cité, ainsi que les épidémies telle la célèbre peste noire de 1348 et ses nombreuses résurgences. Mais Montauban entre surtout dans l'histoire avec l'avènement du protestantisme.

La ville suit un schéma somme toute classique aux XVI ${ }^{e}$ et XVII ${ }^{e}$ siècles : elle bascule rapidement et fortement vers le calvinisme (1559), joue un rôle important dans les guerres de religion, vit ensuite une relative paix religieuse, et subit enfin tous les effets de la contre-réforme catholique que couronne l'Edit de Fontainebleau.

Malgré ces conflits, Montauban des Lumières est une ville importante, tant sur le plan administratif et économique que sur le plan intellectuel et artistique, y compris sous la Révolution qui, dans l'ensemble et comparativement à d'autres villes, laissa assez peu de traces.

Le XIX siècle est, pour Montauban, le commencement du déclin économique et administratif. À l'instar d'un certain nombre de villes méridionales, industrielles ou commerçantes, qui ont connu un brillant XVIII ${ }^{e}$ siècle, la ville connaît également un déclin démographique au siècle suivant. François Grèzer-Rueff insiste, à juste titre, sur le vieillissement parallèle de la population et des structures économiques. À l'écart de la révolution industrielle, Montauban subit tout au contraire une lente mais irréversible désindustrialisation : le textile est en crise, le chômage provoque des 
émeutes (1847-48, -53, -57), la disette menace. L'arrivée du chemin de fer en 1857 ne changera rien : la deuxième moitié du XIX ${ }^{\mathrm{e}}$ siècle ne fait que confirmer, voire amplifier la désindustrialisation de Montauban. Déclin agricole et déclin industriel vont, d'ailleurs, de pair : l'absence de banques, la stagnation des mentalités sont également des facteurs à ne pas négliger.

La vie politique de 1800 à 1939, étudiée par Jean Estèbe. porte l'empreinte, elle aussi, des antagonismes religieux. L'opposition traditionnelle entre catholiques partisans de la restauration monarchique et protestants patriotes y reste globalement valable, au moins jusqu'en 1848. favorisée par le régime impérial --qui créa le département du Tarn-et-Caronne et en fit son chef-lieu--, Montauban connaît une Terreur blanche relativement modérée, passe sans trop de difficultés à une Restauration paisible, une Révolution de Juillet bien accueillie et une monarchie de Juillet qui assure plus la continuité qu'elle ne bouleverse l'ordre établi. Le rôle de la bourgeoisie protestante -Guizot oblige-- s'affirme même si les légitimistes remportent les élections municipales de 1846. 1848 provoque une rupture dans l'ordre politique : le Commissaire de la République Xavier Sauriac s'appuie sur des protestants pour républicaniser l'administration ; il heurte le clan Rous, dont le chef Hippolyte, propriétaire du Courrier du Tarn-et-Caronne, provoque une émeute amenant la prise de l'hôtel de ville et la démission de Sauriac.

Le coup d'État, bien accepté à Montauban, voit se développer une opposition républicaine qui réussit à obtenir $42 \%$ des voix aux élections de 1863 . Mais les députés officiels --Janvier de la Motte jusqu'en 1869, puis Prax-Paris, maire depuis 1860, et député jusqu'en 1902-- ne rencontrent guère de problèmes.

La République va s'ancrer fortement à Montauban, avec des modérés --Gustave Garrisson-- et des radicaux --Irénée Bonnafous--, mais doit lutter jusqu'aux années 1880 contre bonapartistes et conservateurs.

La lutte pour la laïcité dépasse le clivage traditionnel catholiques-protestants. Quant aux socialistes, ils restent très minoritaires avant la Première Guerre mondiale, ne prenant une réelle importance qu'aux élections de 1936. Le parti communiste réussit un faible score.

On notera également l'importance de la vie culturelle, associative et sportive à Montauban. Rappelons que le rugby s'implanta à Montauban en 1904, grâce à des étudiants néo-zélandais de la Faculté de Théologie, protes-tante. Le Félibrige un grand représentant à Montauban, en la personne de l'occitaniste Antonin Perbosc. Quant à J.D. Ingres et A. Bourdelle, ils font figure de gloires locales --à juste titre.

Le volume consacré à Montauban s'achève sur une évocation de la vie politique récente (1940-1983) : la Résistance y fut vigoureuse. Puis, jusqu'à nos jours, radicaux et socialistes s'affrontèrent à chaque consultation électorale, le courant radical incarné par la famille Baylet, le courant socialiste incarné par L. Delmas, le PCF s'intercalant entre les deux.

Bien entendu, cette Histoire de Montauban ne prétend pas être exhaus-tive, mais par sa qualité, son homogénéité et son actualisation, ce livre dresse le portrait d'une cité dont l'histoire se continue. 